\title{
Mental and Emotional Health of Children Exposed to News Media of Threats and Acts of Terrorism: The Cumulative and Pervasive Effects
}

\author{
Marie Leiner ${ }^{1 *}$, Jesus Peinado ${ }^{1}$, Maria Theresa Malazo Villanos ${ }^{1}$, Isis Lopez ${ }^{2}$, \\ Ricardo Uribe ${ }^{2}$ and Indu Pathak ${ }^{1}$ \\ ${ }^{1}$ Pediatrics, Texas Tech University Health Sciences Center, El Paso, TX, USA, ${ }^{2}$ Paul L. Foster School of Medicine, Texas \\ Tech University Health Sciences Center, EI Paso, TX, USA
}

Keywords: violence exposure, pediatric populations, terrorism news, disparities, trauma

\section{OPEN ACCESS}

Edited by:

Frederick Robert Carrick,

Carrick Institute, USA

Reviewed by:

Rashid Zaman,

University of Cambridge, UK

Ahmed Hankir,

Bedfordshire Centre for Mental Health Research in association with

Cambridge University, UK

${ }^{*}$ Correspondence:

Marie Leiner

marie.leiner@ttuhsc.edu

Specialty section:

This article was submitted to Child Health and Human Development,

a section of the journal

Frontiers in Pediatrics

Received: 11 January 2016

Accepted: 10 March 2016

Published: 23 March 2016

Citation:

Leiner M, Peinado J, Villanos MTM, Lopez I, Uribe R and Pathak I (2016) Mental and Emotional Health of

Children Exposed to News Media of Threats and Acts of Terrorism: The Cumulative and Pervasive Effects.

Front. Pediatr. 4:26.

doi: 10.3389/fped.2016.00026
Viewing extreme violence and terrorism, either directly by witnessing acts or indirectly by watching them in the media, affects children's mental and emotional health (1), and some children are at a higher risk for negative effects than others. Indirect exposure to terrorism acts and threats through the media affects the mental health of children, in both short- and long-term ways that differ completely from the effects in adults. Children's vulnerability, immaturity, and developmental state change their perspective, and the tools used to confront these issues do not affect each child equally. Additionally, emotional problems might not surface immediately; instead, they can remain latent until they surface eventually. How and when this occurs depends mostly on additive effects generated by the environment in which the child develops and additional disparities in which the child confronts.

The Federal Bureau of Investigation (FBI) defines terrorism as "the unlawful use of force or violence against persons or property to intimidate or coerce a government, the civilian population, or any segment thereof, in furtherance of political or social objectives" (2). Direct or indirect exposure to terrorism violence provokes a state of terror in the general public through the use of calculated acts of violence, which includes murder, mutilation, and explosions that affect innocent people, often including children. Even though the events might no longer be in the news, the psychological scars and trauma caused by viewing the horrifying images and by the memories are pervasive and do not heal easily (3). The natural tendency of adults to try to forget about the problems and move on with their lives often results in underestimating the importance and effect of the exposure on the emotional and psychosocial problems of children.

The negative effect of exposure to violence in the media on children has been extensively discussed for years, with many controversial and conflicting results and conclusions. While some have found highly negative effects (4-6), others have denied any possible effects from media exposure $(7,8)$. Nevertheless, the existing evidence about the effects of media exposure to terrorism and violence acts among children should not be underestimated or dismissed. The point of discussion here is to consider the need to support strategies that reduce the effects of unsupervised viewing of terrorism acts and threats presented by the media. While stopping the media presentation of this violence might not be possible, there is much room to consider strategies that can reduce and help to better understand the effects of violence on the emotional health of children at home, in school, and in health sector. The media itself can also help by increasing the attention given to these strategies. 


\section{AVAILABILITY AND REPETITION OF UNRESTRICTED MEDIA}

Children today have virtually unrestricted access to worldwide media coverage of terrorism acts, which threatens their mental and physical health due to their crude nature. Terrorist acts have been documented throughout history, but in the last decades, media coverage has given unfair attention to these despicable acts of shocking violence.

Media access brings worldwide events very close to children, and often in a very crude way, through the news, Internet, or social media. It can involve intrusive, unedited images portraying extreme acts of violence that can be very intense $(9,10)$. Children do not have a sense of spatiality and rarely understand the concept that these events have occurred far from their current location. Instead, these almost live events can cause feelings of unsafety, hopelessness, and helplessness, which are often externalized by conduct problems.

The effects of indirect exposure to violence affect younger children more than older children (11), and research indicates that real exposure to war events in children below age 10 increases their risk of developing internalizing disorders in later life (12). This was also demonstrated by two studies that compared exposure to drug cartel terrorism (collective violence) among children on both sides of the US-Mexican border. These studies included children at different ages (1.5-5 and 6-16 years) and examined the cumulative effect of poverty and collective violence (terrorism) $(11,13)$.

In Mexico, news about mass murders of men, women, and children was broadcasted repeatedly for days and months by multiple outlets, including radio stations, newspapers, and television networks. The media presented the death of activists and bystanders with extreme crudeness, including covering many acts of terror, such as mutilations, bombings, kidnappings, tortured bodies, and decapitations.

When comparing the psychosocial and behavioral problems of children (6-16 years old) on each side of the border, the studies found that, on the Mexican side, the externalizing of problems from exposure to collective violence increased. The younger Mexican children had a threefold increase in emotional and behavioral problems when compared to their US counterparts who were not confronted by this indirect mass media victimization. Young Mexican children also had higher scores than their US counterparts for most emotional and behavioral scales, including mild/severe brain injury (14); single-suture craniosynostosis (15); parental history of cocaine, alcohol, tobacco, and marijuana exposure (16); prenatal cocaine exposure (17); maternal current and past depression (18); and hearing impairment (19). The excessive amount of exposure to viewing violent events can have a profound effect on children's sense of security, leaving strong feelings of vulnerability and resulting in emotional and psychological trauma, even though these events are only presented by the media $(20-22)$. These studies have some limitations, including their cross-sectional study design. In addition, given the amount of news in the city about generalized violence, for these studies, it was assumed that families were indirectly victimized when they could be both direct and indirect victims of violence. Available information did not include specifics about this additional effect on the families.

\section{THE EFFECT OF INEQUALITY AND ADVERSITY AND THEIR RELATIONSHIP WITH EXPOSURE TO VIOLENCE}

Not all children are fortunate enough to live with parents who can provide them with the human and social experiences that are essential for children to help them thrive and grow into healthy, productive adults. Children confronting inequalities due to poverty and low socioeconomic status must contend with increased exposure to violent events during their life span (23), which will have a profound effect in their mental and physical health. Often, children living with these inequalities are at a higher risk of confronting direct and indirect victimization, which may be just one event in a series of adverse events. The emotional outcome of a child will always reflect the cumulative load of these stressful events.

The CDC-Kaiser Adverse Childhood Experiences (ACE) study demonstrated the harmful, immediate, and long-lasting effects that adversity has on child development (19). The immediate cognitive effects reported included attention problems, learning disorders, and poor school performance. Children who experience adversity-related problems may suffer decades later from chronic disease and mental illness and may display aggressive and violent behaviors as adults. In addition, direct or indirect exposure to violence is recognized as an adverse childhood experience that can become a form of victimization and is considered a basic cause of morbidity and mortality in adults (24-26).

\section{CHILD DEVELOPMENT AND CHRONIC STRESS}

Excessive or prolonged activation of stress response systems in a child can have damaging effects on learning, behavior, and health across a person's life span. Constantly viewing threatening images and acts of violence produce episodes of stress that increases a child's heart rate and blood pressure as well as the production of stress hormones. Because of their age, children do not have the resources to manage this stress, which can disrupt the development of brain architecture and other organ systems with lifelong consequences. The elevated stress levels may last longer than in an adult, interrupting the natural process of development causing physical cognitive and emotional problems $(27,28)$.

\section{CONCLUSION}

Reports of terrorism events indicate that, in 2015, there were at least 21 terrorist attacks around the world where 50 or more people were killed. Six of those attacks killed more people than those who were killed in the France attacks (29). The events that get the maximum attention are often the deadliest or those perpetuated with the maximum hate, blood, and gore. Both direct and indirect effects of terrorism violence affect adults and have strong implications for their physical and mental health (20). Adults are better equipped to deal with both physical and emotional effects, and 
therefore accounting for the effects of this violence on children requires a broad understanding of children's vulnerabilities $(30,31)$. Children's developmental stages limit their abilities to describe their symptoms, communicate their wants or needs, and seek assistance (32).

Exposure to terrorism violence through the media, videogames, movies, or news about disasters and/or individual incidents has different implications for the pediatric population, and multiple studies have shown a link to adverse mental health effects in children. These findings emphasize the need and importance for primary care providers to receive training (33) to better assess and refer children who need therapy to confront and deal with these emotional effects. The effects of exposure to terrorism violence on children might not be apparent for several days, months, or even years. The effects are dosed and triggered by existing psychological problems, adversity, and/or previous victimization.

Addressing the effects of terrorism violence acts involves much more than just taking care of the direct victim's needs, it requires considering that the bystanders watching these acts in the media are highly vulnerable as well. Planning appropriate preventative measures, including restricting media use, parental education, and early detection of emotional problems, can help prevent the problems that we confronted after media exposure during the September 11th terrorism events. The long-term effects of media exposure to terrorism events are still largely unknown, and the current mental health system has been ineffective in identifying and dealing with the mental health needs of children that these acts of terrorism have created $(34,35)$.

Early intervention services to improve outcomes for children have a tremendous impact on children's lives as well as the lives of their families and society as a whole. Treatment for those at a higher risk is a recognized challenge, especially among those from a lower socioeconomic status or minority backgrounds.

\section{REFERENCES}

1. Jackson R, Breen-Smyth M, Gunning J, Jarvis L. Terrorism: A Critical Introduction. London: Palgrave Macmillan (2011).

2. Terrorism. Office of justice programs. In: Topics: Crime and Prevention. Washington, DC: National Institute of Justice (2011).

3. Joshi PT, Fayyad JA. Displaced children: the psychological implications. Child Adolesc Psychiatr Clin N Am (2015) 24(4):715-30. doi:10.1016/j. chc.2015.06.003

4. Leiner M, Peinado J, Villanos MT, Alvarado LA, Singh N, Dwivedi A. Psychosocial profile of Mexican American youths who play aggressive video games. Hisp J Behav Sci (2014) 36(3):301-15. doi:10.1177/0739986314538603

5. Anderson CA, Carnagey NL. Causal effects of violent sports video games on aggression: is it competitiveness or violent content? J Exp Soc Psychol (2009) 45(4):731-9. doi:10.1016/j.jesp.2009.04.019

6. Anderson CA, Carnagey NL, Flanagan M, Benjamin AJ, Eubanks J, Valentine JC. Violent video games: specific effects of violent content on aggressive thoughts and behavior. Adv Exp Soc Psychol (2004) 36:200-51. doi:10.1016/j. jesp.2009.04.019

7. Rosenberg M, Lay B, Lee M, Derbyshire A, Kur J, Ferguson R, et al. Newgeneration active videogaming maintains energy expenditure in children across repeated bouts. Games Health J (2013) 2(5):274-9. doi:10.1089/g4h.2013.0037

8. Ferguson B. Videogames: the good, the bad, and the ugly. Games Health J (2013) 2(1):1-2. doi:10.1089/g4h.2013.1015
Referrals, if necessary, for follow-up may not occur in many cases due to economic, cultural, health literacy, language proficiency, and educational disparities. Therefore, an additional counseling is required to inform parents and youth about the benefits of follow-up therapy.

Opportunities to help families mitigate the harmful effects of adversity, inequalities, and exposure to violence need to be considered and nurtured to help make a difference in the life of a child. While the direct effect that wars have on children is well understood, the indirect effects that unrestricted access to terrorism views have on children is not only less understood but also important to understand. Dismissal of the detrimental mental and emotional effects on children, despite the available evidence, will only add to the societal burden from the emotional stress and suffering. With better awareness and proper measures to monitor children's access to violent acts, we can improve their quality of life and the future of our society.

\section{AUTHOR CONTRIBUTIONS}

ML made substantial contributions to conception and design of idea, participated in drafting the article, and approval of the version to be submitted. JP made substantial contributions to conception and design of idea, participated in drafting the article, and approval of the version to be submitted. MV made substantial contributions to conception and design of idea, participated in drafting the article, and approval of the version to be submitted. IP made substantial contributions to conception and design of idea, participated in drafting the article, and approval of the version to be submitted. IL and RU made substantial contributions to idea discussion, revised critically the article, and gave final approval of the version to be submitted.

9. Pfefferbaum B, Nixon SJ, Tivis RD, Doughty DE, Pynoos RS, Gurwitch RH, et al. Television exposure in children after a terrorist incident. Psychiatry (2001) 64(3):202-11. doi:10.1521/psyc.64.3.202.18462

10. Pfefferbaum B. The impact of the Oklahoma City bombing on children in the community. Mil Med (2001) 166(12 Suppl):49-50.

11. Leiner M, Villanos MT, Puertas H, Peinado J, Ávila C, Dwivedi A. The emotional and behavioral problems of children exposed to poverty and/or collective violence in communities at the Mexico-United States border: a comparative study. Salud Ment (2015) 38(2):95-102. doi:10.17711/SM.0185-3325.2015.013

12. Karam EG, Mneimneh ZN, Dimassi H, Fayyad JA, Karam AN, Nasser SC, et al. Lifetime prevalence of mental disorders in Lebanon: first onset, treatment, and exposure to war. PLoS Med (2008) 5(4):e61. doi:10.1371/journal. pmed.0050061

13. Leiner M, Puertas H, Caratachea R, Avila C, Atluru A, Briones D, et al. Children's mental health and collective violence: a binational study on the United States-Mexico border. Rev Panam Salud Publica (2012) 31(5):411-6. doi:10.1590/S1020-49892012000500009

14. Wetherington CE, Hooper SR, Keenan HT, Nocera M, Runyan D. Parent ratings of behavioral functioning after traumatic brain injury in very young children. J Pediatr Psychol (2010) 35(6):662-71. doi:10.1093/jpepsy/jsp081

15. Kapp-Simon KA, Collett BR, Barr-Schinzel MA, Cradock MM, Buono LA, Pietila KE, et al. Behavioral adjustment of toddler and preschool-aged children with single-suture craniosynostosis. Plast Reconstr Surg (2012) 130(3):635-47. doi:10.1097/PRS.0b013e31825dc18b 
16. Accornero VH, Morrow CE, Bandstra ES, Johnson AL, Anthony JC. Behavioral outcome of preschoolers exposed prenatally to cocaine: role of maternal behavioral health. J Pediatr Psychol (2002) 27(3):259-69. doi:10.1093/ jpepsy/27.3.259

17. Lindhiem O, Dozier M. Caregiver commitment to foster children: the role of child behavior. Child Abuse Negl (2007) 31(4):361-74. doi:10.1016/j. chiabu.2006.12.003

18. Dietz LJ, Jennings KD, Kelley SA, Marshal M. Maternal depression, paternal psychopathology, and toddlers' behavior problems. JClin Child Adolesc Psychol (2009) 38(1):48-61. doi:10.1080/15374410802575362

19. Barker DH, Quittner AL, Fink NE, Eisenberg LS, Tobey EA, Niparko JK, et al. Predicting behavior problems in deaf and hearing children: the influences of language, attention, and parent-child communication. Dev Psychopathol (2009) 21(2):373-92. doi:10.1017/S0954579409000212

20. Ahern J, Galea S, Resnick H, Kilpatrick D, Bucuvalas M, Gold J, et al. Television images and psychological symptoms after the September 11 terrorist attacks. Psychiatry (2002) 65(4):289-300. doi:10.1521/psyc.65.4.289.20240

21. Fairbrother G, Stuber J, Galea S, Fleischman AR, Pfefferbaum B. Posttraumatic stress reactions in New York City children after the September 11, 2001, terrorist attacks. Ambul Pediatr (2003) 3(6):304-11. doi:10.1367/1539-4409(2 003)003<0304:PSRINY>2.0.CO;2

22. Otto MW, Henin A, Hirshfeld-Becker DR, Pollack MH, Biederman J, Rosenbaum JF. Posttraumatic stress disorder symptoms following media exposure to tragic events: impact of $9 / 11$ on children at risk for anxiety disorders. J Anxiety Disord (2007) 21(7):888-902. doi:10.1016/j.janxdis.2006.10.008

23. Wade R Jr, Shea JA, Rubin D, Wood J. Adverse childhood experiences of low-income urban youth. Pediatrics (2014) 134(1):e13-20. doi:10.1542/ peds.2013-2475

24. Felitti VJ, Anda RF, Nordenberg D, Williamson DF, Spitz AM, Edwards $\mathrm{V}$, et al. Relationship of childhood abuse and household dysfunction to many of the leading causes of death in adults. The Adverse Childhood Experiences (ACE) study. Am J Prev Med (1998) 14(4):245-58. doi:10.1016/ S0749-3797(98)00017-8

25. Chapman DP, Whitfield CL, Felitti VJ, Dube SR, Edwards VJ, Anda RF. Adverse childhood experiences and the risk of depressive disorders in adulthood. JAffect Disord (2004) 82(2):217-25. doi:10.1016/j. jad.2003.12.013

26. Dong M, Giles WH, Felitti VJ, Dube SR, Williams JE, Chapman DP, et al. Insights into causal pathways for ischemic heart disease: adverse childhood experiences study. Circulation (2004) 110(13):1761-6. doi:10.1161/01. CIR.0000143074.54995.7F
27. Lim L, Radua J, Rubia K. Gray matter abnormalities in childhood maltreatment: a voxel-wise meta-analysis. Am J Psychiatry (2014) 171(8):854-63. doi:10.1176/appi.ajp.2014.13101427

28. Sherrieb K, Norris FH. Public health consequences of terrorism on maternal-child health in New York City and Madrid. J Urban Health (2013) 90(3):369-87. doi:10.1007/s11524-012-9769-4

29. Bump P. 2015 Has Seen Six Terror Attacks Deadlier than Paris. Washington Post. Washington, DC: Washington Post (2015).

30. Barfield WD, Krug SE, Kanter RK, Gausche-Hill M, Brantley MD, Chung S, et al. Neonatal and pediatric regionalized systems in pediatric emergency mass critical care. Pediatr Crit Care Med (2011) 12(6 Suppl):S128-34. doi:10.1097/ PCC.0b013e318234a723

31. Bartenfeld MT, Peacock G, Griese SE. Public health emergency planning for children in chemical, biological, radiological, and nuclear (CBRN) disasters. Biosecur Bioterror (2014) 12(4):201-7. doi:10.1089/bsp.2014.0036

32. Antommaria AH, Powell T, Miller JE, Christian MD; Task Force for Pediatric Emergency Mass Critical. Ethical issues in pediatric emergency mass critical care. Pediatr Crit Care Med (2011) 12(6 Suppl):S163-8. doi:10.1097/ PCC.0b013e318234a88b

33. Adams RE, Laraque D, Chemtob CM, Jensen PS, Boscarino JA. Does a one-day educational training session influence primary care pediatricians' mental health practice procedures in response to a community disaster? Results from the reaching children initiative (RCI). Int J Emerg Ment Health (2013) 15(1):3-14.

34. Schonfeld DJ. Supporting adolescents in times of national crisis: potential roles for adolescent health care providers. J Adolesc Health (2002) 30(5):302-7. doi:10.1016/S1054-139X(02)00382-8

35. Hagan JF Jr; American Academy of Pediatrics Committee on Psychosocial Aspects of Child and Family Health, Task Force on Terrorism. Psychosocial implications of disaster or terrorism on children: a guide for the pediatrician. Pediatrics (2005) 116(3):787-95. doi:10.1542/peds.2005-1498

Conflict of Interest Statement: The authors declare that the research was conducted in the absence of any commercial or financial relationships that could be construed as a potential conflict of interest.

Copyright (c) 2016 Leiner, Peinado, Villanos, Lopez, Uribe and Pathak. This is an open-access article distributed under the terms of the Creative Commons Attribution License (CC BY). The use, distribution or reproduction in other forums is permitted, provided the original author(s) or licensor are credited and that the original publication in this journal is cited, in accordance with accepted academic practice. No use, distribution or reproduction is permitted which does not comply with these terms. 